1 Web-based Outreach for Orchard Management Decision-Makers

2 Wendy E. Jones ${ }^{\mathrm{a} *}$, Ute Chambers ${ }^{\mathrm{a}}$, Angela Gadino ${ }^{\mathrm{a}}$ and Jay F. Brunner ${ }^{\mathrm{a}}$

$4 \quad{ }^{a}$ Department of Entomology, Tree Fruit Research and Extension Center, Washington

5 State University, $1100 \mathrm{~N}$ Western Ave., Wenatchee, WA 98801 United States

6 *Corresponding Author: wendyej@ wsu.edu, 1100 N Western Ave., Wenatchee, WA, $7 \quad 98801$

8 1-509-663-8181 ext. 260 (office), 1-509-662-8714 (fax)

10 Abstract

11 The traditional role of extension has been to provide the bridge between research-

12 generated knowledge and technology to stakeholders through instruction, practical

13 demonstrations, and developing applications of existing, improved or novel practices and

14 technology. However, the number of educators and extension specialists has been

15 decreasing and their roles changing, while stakeholder groups have become more

16 dependent on timely information to cope with rapid changes in management programs.

17 These circumstances necessitate a change in the way information delivery occurs. A key

18 component of the outreach objective in this project was to develop web-based tools to

19 speed the dissemination of research information to decision-makers. Web-based outreach

20 is intended to supplement, but not replace, extension personnel. Hands-on training and

21 direct interaction with the stakeholders is still necessary to insure that relevant

22 information is not just delivered but understood. Here we discuss how our web-based

23 outreach integrates with traditional training as well as other digital information sources

24 available into the future.

\title{
26 Keywords
}

27 biological control, online outreach, orchard management, pesticide effects, social media, 28 decision support tools

\section{1. Introduction}

31 Cooperative Extension has undergone a significant broadening of its programs and client

32 base since its inception in 1914 and especially since the later part of the $20^{\text {th }}$ century 
33 (Vine et al., 1963; Ratchford, 1984; Urbanowitz and Wilcox, 2013). Whereas the initial

34 focus was on agriculture, $4 \mathrm{H}$, and rural development, it now includes additional areas

35 such as urban family and community development, consumer science and youth

36 development (Diekmann, et al., 2012; Warner et al., 1998). The increased activity in new

37 program areas and with more diverse clientele has paralleled a decrease in federal and

38 state funding for extension. In the past, the primary focus of Cooperative Extension in

39 agriculture was to provide farmers with research-based information through a network of

40 county-based agents and university-based specialists. As the number of extension

41 personnel has declined, service areas have increased along with an increasing demand for

42 a broader knowledge base. The traditional information transfer model used by extension

43 was to have researchers share results with university-based specialists who then

44 interpreted, summarized and delivered the information to county-based agents for wider

45 public dissemination through vehicles such as demonstration projects, stakeholder

46 meetings and newsletters. A drawback with this model is its high cost in terms of

47 personnel time and travel, especially when extension budgets and the workforce are

48 shrinking. One way to address the loss of funding is to include outreach objectives within

49 research grants. This is only a short-term solution because once the grant has completed,

50 Extension in most cases does not have the capacity to sustain programming that was

51 developed during the grant. Another problem is that the traditional model is estimated to

52 take seven years to go from information transfer to implementation of new technology or

53 practices in agriculture (Alston et al., 1995). This lag time is too long to respond to

54 problems such as invasive pests or diseases that require fast turn-around on knowledge

55 delivery. With the Internet being more accessible even in rural communities (Bonlender,

56 2013; Horrigan, 2010), the use of web-based programs provides an effective solution to

57 help speed the delivery of research-based knowledge, educational materials, training, and

58 decision support systems (Jones et al., 2009). While face-to-face meetings and on-site

59 instruction are the long-time favorites of both Extension and the agricultural community,

60 in reality they are too costly to be the primary form of outreach in the current funding

61 climate. Electronic forms of information make outreach more cost effective and more

62 responsive to emerging issues (Jones et al., 2009; Schneider et al., 2011; Trede and

63 Whitaker, 1998). Therefore, one objective of our Specialty Crop Research Initiative 
64 (SCRI) project focused much of its outreach programming on the development of web-

65 based components containing new information generated by the researchers, such as

66 visual guides, multi-media and interactive information tools requiring little or no

67 maintenance that would be useful well beyond the completion of the project. A more

68 complete explanation about all project objectives and their execution can be found in in

69 the introductory article of this issue (Jones et al., 2016, this issue).

\section{2. Stakeholders and Information Transfer}

71 At the project onset, Pacific Northwest growers, orchard managers and crop consultants

72 with responsibilities in apple, pear and walnut were surveyed to determine how they

73 preferred to receive information and if they accessed the Internet looking for this

74 information. The majority of pear growers (93\% in Oregon and 82\% in Washington)

75 indicated that they use computers for farm business and 75\% regularly access the Internet

76 to acquire farming information (Goldberger and Lehrer, 2016, this issue). These results

77 meet or exceed state and national means from concurrent NASS surveys on farm

78 computer usage and ownership (NASS, 2009, 2013). Washington apple growers and crop

79 consultants had a difference of opinion about their preferences in receiving farm

80 management information. Although the majority of both groups preferred face-to-face

81 delivery methods, nearly $60 \%$ of the consultants also accessed web resources compared

82 to about $36 \%$ of growers (Gadino, 2012). A similar pattern of correlation was seen for

83 NASS data on California farmers and our survey data from California walnut growers

84 (Goldberger and Lehrer, 2016, this issue).

85 Based on participant preferences from our surveys (Gadino, 2012; Goldberger and Lehrer,

86 2016, this issue) and suggestions from the literature (Kallioranta et al., 2006; Kinsey,

87 2010; Ray, 2007), we launched a broad spectrum of Internet resources including a

88 dedicated project website, a blog, and several forms of social media. The purpose of the

89 website was to inform stakeholders about the project and keep them updated about its

90 progress and new information that was being generated. The blog and other social media

91 sites were employed for a more direct interaction with stakeholders and to promote latest

92 research findings and outreach events with links to more detailed information on the

93 project website. 


\section{3. The Project Website \\ 95 3.1. Website Content}

96 The content of the project's website was geared towards stakeholders (growers and crop

97 consultants) and the scientific community by delivering basic, newly generated and

98 synthesized information on enhancing biological control in orchards

99 (http://enhancedbiocontrol.org). Upon entering the website, visitors were presented with a

100 short synopsis about the project, spotlights of featured content and a revolving slideshow

101 of project related events and information. The website was easily navigated using the

102 menu at the top of the page (Figure 1). The majority of the project output fell under the

103 Features heading. From there, visitors could get more detailed information about the

104 project members and objectives or follow the project's progress by browsing through or

105 downloading annual reports, survey results, lists of presentations, posters, and articles

106 published in scientific journals and trade magazines. Synthesized results from the

107 pesticide effects studies were also located under this heading (see Section 3.2 below), as

108 well as a section with downloadable resources for identifying natural enemies. The

109 remainder of the content fell under the separate menu headings Galleries (natural enemies

110 image galleries) and Videos (topic sortable video gallery) making access to these

111 resources more visible.

112 The website also served as a hub for advertisement and registration for the two-day

113 interactive short course on orchard biological control offered in 2012 (Gadino et al., 2016,

114 this issue). After the short course was completed the advertisement page was converted to

115 a resource page hosting downloadable course materials and viewable presentations

116 (http://enhancedbiocontrol.org/BC_SC.html).

\section{3.2. Pesticide Effects Information and OPENED}

118 A major focus of the project website was to educate stakeholders about the newly

119 discovered sublethal effects of certain pesticides on natural enemies (Mills et al., 2016,

120 this issue) and to deliver this information in a fashion that would help them in their pest

121 management decision-making process. Visitors to the website learn about sublethal

122 effects of pesticides through the lens of limitations on population growth. The research 
123 results were summarized in an interactive table showing impacts on overall population

124 growth for each pesticide-natural enemy combination

125 (http://enhancedbiocontrol.org/PE.html). The table was color-coded for better

126 visualization of the effect ratings (Figure 2). Visitors mouse-click (desktop or laptop

127 browser) or touch (tablet or smartphone browser) a table cell to view more detailed

128 information, such as acute toxicity or individual sublethal effects for a specific pesticide

129 on a specific natural enemy.

130 The initial idea to compare project information of sublethal pesticide effects on natural

131 enemies with other similar available data led to the development of the Orchard Pesticide

132 Effects on Natural Enemies Database (OPENED; http://enhancedbiocontrol.org/opened/).

133 In OPENED, pesticide toxicity ratings for selected pesticides and natural enemies

134 relevant in orchards in the Pacific Northwest region were compiled from various sources ${ }^{1}$.

135 Details on how the data on sublethal pesticide effects was derived during the course of

136 this project can be found in accompanying articles in the this issue (Amarasekare et al.,

137 2016; Beers et al., 2016a, 2016b; Mills et al., 2016; Shearer et al., 2016; all this issue).

138 OPENED can be searched by individual pesticide or by crop and target pest, which then

139 lists all recommended pesticides, for example, to control codling moth in apple (Figure 3).

140 The search result shows a color gradient for each pesticide representing the range of

141 known pesticide effects on all natural enemies included in the database (green $=$ no or

142 low, yellow $=$ moderate, and red $=$ high negative effects $)$. The number within the color

143 gradient $(\mathrm{n}=\#)$ indicates how many data points (natural enemies and/or source entries)

144 were included in the gradient and whether the effects were based on population growth or

145 acute toxicity ratings. In OPENED, population growth effects override any data based

146 solely on acute toxicity, as population growth provided a more complete representation of

147 a pesticide's risk of negative impacts on a particular natural enemy. The population

148 growth effects are labeled with a star to clearly indicate the difference. Search results can

149 be further filtered to separate out effects on natural enemies that consume a particular

150 type of secondary pest such as aphids or mites. This filter allows growers and

151 stakeholders to specify which secondary pests have been or are the current problem in

152 their orchards. The table then returns additional columns with pesticide effects for these 
153 groups of natural enemies that contribute to the biological control of those secondary

154 pests. With this approach users are not required to have detailed knowledge about

155 specific natural enemy species. For easy comparison, users can sort the list by pesticide

156 effects ratings or any other parameter in the table.

157 OPENED data has been incorporated into the WSU Crop Protection Guide for Tree Fruit

158 (Beers et al., 2015) as well as the Washington State University Decision Aid System's

159 (WSU-DAS; https://das.wsu.edu) pest control database, thus delivering pesticide effects

160 information to virtually the entire Washington state tree fruit industry. Currently,

161 OPENED mainly contains registered pesticides that are recommended by WSU

162 Extension for tree fruit. However, the OPENED database could be set up to

163 accommodate other states if desired and, as funding becomes available, for updating or

164 adding new information.

\section{3.3. Social Media Companions to the Website}

166 In addition to the more traditional routes of information transfer, we turned to social

167 media, such as YouTube for video hosting, Facebook and Twitter for networking, and

168 Blogger for blogging. An increasing number of extension programs around the country

169 have successfully enlisted the use of social media to connect with clientele when frequent

170 face-to-face interactions are not feasible (Cornelisse et al., 2011). In many situations,

171 social media has been used to help promote educational events, give quick links to in-

172 depth resources, and quickly respond to immediate problems or questions (Cornelisse et

173 al., 2011; Kinsey, 2010; Schneider et al., 2011). With the short turn-around time

174 associated with grant funded projects, we wanted to take advantage of the large

175 popularity of social media outlets to boost the quick dissemination of our research results

176 and help advertise learning opportunities with our stakeholders.

177 With over 3,000 viewings of the project videos as of December 2015, hosting all videos

178 on YouTube has been a very successful strategy. YouTube is rated by eBiz (2014) to be

179 the most versatile tool with a strong overall popularity. Our videos are publicly accessible

180 in a project-dedicated channel entitled "Enhanced Biocontrol" as well as being embedded

181 within our website's video gallery page and on the project blog. This gives the public 
182 multiple ways to find and view the videos, subscribe to our YouTube channel, search by

183 title or keyword, or visit our website video page. Having a dedicated YouTube channel

184 allowed us to add relevant videos posted by others, thereby catering to the broader

185 interest of our clientele and increasing the impact of our research. For example, we

186 included a video interview of the project director Dr. Vince Jones produced by the

187 University of California College of Agriculture and Natural Resources, describing the

188 future outlook of IPM and biocontrol in orchard systems

189 (http://www.youtube.com/watch?v=ILxGlf3HioA).

190 We also set up both a Facebook page (http://facebook.com/Western-Orchard-Biocontrol)

191 and a Facebook Profile (https://www.facebook.org/EnhancedBC) to test which would be

192 easier to manage and attract "friends". Although both ended up with the same number of

193 friends (25), the page version was easier to manage. We also set up a Twitter feed

194 (https://twitter.com/EnhancedBC). Both the Facebook page and Twitter feed were set up

195 to inform the apple, pear and walnut communities about project related activities,

196 including the release of new videos, recent articles published in trade magazines, to post

197 relevant stories, and to advertise events and new features on the project web site. Links to

198 both the Facebook page and Twitter feed were located in the footer section on all project

199 website pages for easy access. However, a disadvantage for both media types was the

200 limitation on the amount and format of content that could be posted. Twitter posts were

201 limited to 140 characters, which was useful for posting a brief headline and a shortened

202 page link for more information. And although Facebook posts can be long, short posts are

203 more common and may contain an image or link to another page or posting. To overcome

204 this obstacle we created a blog (http://ewobc.blogspot.com). Blogs, short for web logs,

205 are not in themselves as quick a mode of information dissemination as the other methods,

206 but do allow for nearly unlimited story length with an appearance that can mirror that of

207 the main project website. However, blogs can be set up to link to Facebook and/or

208 Twitter to instantly post an announcement that a new story has been added to the blog

209 including a direct link. Blogs have the added ability to allow (and later turn off) open or

210 reviewed commenting on the articles where the blog author can reply back to the

211 comments or delete any inappropriate comments. To help increase the popularity of the

212 blog we linked it to both the Facebook page and Twitter feed so that whenever a new 
213 article was posted a notification would appear on each. We also included a link to help

214 drive viewer traffic back to the main website.

\section{3.4. Stakeholders' Web Use and Technical Considerations}

216 For Internet resources to be utilized, they need to be accessible, relevant and meet a need

217 of the target audience (Zickuhr and Smith, 2012). According to NASS surveys regarding

218 on-farm computer and Internet usage, $70 \%$ of US farms reported having access to

219 computers and 67\% had Internet access in 2013, a 6\% and 8\% increase from 2009,

220 respectively (NASS, 2009, 2013). Both computer use and Internet access in California,

221 Oregon, and Washington exceeded the national values (Table 1). This indicates that the

222 stakeholders targeted by this project should be able to readily access the project's web

223 resources. By the end of the first year (November 2009), the project website, which then

224 mainly contained information about project goals, research objectives and personnel

225 involved, received about 1,600 total page views. Over time, page views gradually

226 increased and reached a total of over 22,000 by August 2014 when the project had

227 finalized. The project videos were very popular with over 3,000 views as of December

228 2015. OPENED has become the most popular page (15\% of page views by December

229 2015) outside of the homepage on the site, even though it was only added in January

230 2014. Website visitor data was collected initially using Statcounter.com then switched to

231 Google Analytics beginning in November 2012 for its enhanced interface and unlimited

232 free data storage. Regardless of the collection method, there was a limitation to the depth

233 of data metrics. Since the website was open access, i.e., did not require a login and user

234 profile, no demographic data could be collected. We were limited to information gleamed

235 from Internet service provider data. Unique website visitors were defined through a

236 combination of information about location (closest city), operating system, device type

237 and monitor resolution. Looking at a breakdown of the website user metrics, we

238 determined that of the 7278 users within the United States, 33.9\% were from Washington,

$23911.8 \%$ were from Oregon and $10.2 \%$ were from California, and were ranked the top three

240 states, respectively. This aligned favorably with the locations of our target audience. To

241 determine success of website engagement we looked to the information gathered from the

242 grower surveys conducted at the beginning of the project (Gadino, 2012; Goldberger et al, 
243 2013; Goldberger and Lehrer 2016, this issue). Table 2 summarizes information from the

244 surveys and shows the total number of growers in each grower group with the percent

245 responding to the survey and the number of individuals stating that they used university

246 web resources for management information. The number of website users exceeds the

247 number of growers using this type of resource indicating the possibility of engaging our

248 primary audience. The excess users may reflect engagement by our secondary audience

249 comprised of crop consultants, extension personnel and researchers, as well as by non-

250 target viewers.

251 The increase in website visits over the years can be attributed to the website becoming

252 more relevant and also more "visible" to search engines as more content was added.

253 Intensive promotion of the website at stakeholder meetings and in trade magazine articles

254 was also a likely contributor to the increased website traffic. The importance of adding

255 relevant content and advertisement is reflected in the annual and monthly page views

256 (Figure 4). The spikes in monthly page views corresponded with (1) a major website

257 update including improved mobile browsing and the addition of the 2010 annual report

258 and survey results; (2) stakeholders looking for information about the two-day biological

259 control short course held in February 2012 (Gadino et al, 2016, this issue); and (3) the

260 launch and promotion of OPENED. Even though the research portion of the project was

261 completed in August 2013, the monthly page views have remained high indicating that

262 the material continues to be relevant as a basic resource for orchard biological control

263 information.

264 Social media like blogs, Facebook or Twitter, on the other hand, represent more novel

265 and specialized ways of interacting with stakeholders. According to a Pew Research

266 Center report, $72 \%$ of online adults used some form of social media in 2012 (Brenner and

267 Smith, 2013). Although younger adults were thought to be the most likely users, the

268 number of older adult users had strongly trended upwards since 2009. However, the Pew

269 Internet survey did not address the type of work engaged in by those surveyed, therefore,

270 no conclusions could be drawn for our particular target audience. When California,

271 Oregon and Washington growers and consultants were asked how they preferred to

272 receive information about biological control, social media ranked below all other forms 
273 of communication (Gadino, 2012; Goldberger and Lehrer, 2016, this issue). This low

274 ranking was reflected in the rather disappointing numbers of Facebook friends (25) and

275 Twitter followers (27) that connected with the project through these outlets. Our blog was

276 more popular with over 2860 views as of December 2015.

277 The challenge with all three social media outlets was to obtain relevant news stories or

278 images from project members for publishing online. If social media pages are not updated

279 on a regular basis, viewers loose interest and stop following. Many could interpreted this

280 dilemma as a chicken-and-egg problem: "why invest in social media when there is no

281 interest from the stakeholders to use it?" versus "stakeholders would visit more if there

282 was relevant information or interesting updates." In fact, a shift in researcher or extension

283 personnel attitude (and also their rewards system) is needed to encourage frequent

284 postings of short and attention grabbing items, with links to more detailed articles if

285 suitable. Only then will stakeholders on social media grow in numbers and keep coming

286 back for more news (Cornelisse, et al., 2011).

287 Representing the multi-institutional aspect of the project was a technical challenge

288 requiring the development of a unique design layout that highlighted the content over any

289 specific organization's identity. The website address (URL) was also selected to reflect

290 this intent necessitating the purchase of descriptive and non-institutional domain names,

291 http://enhancedbiocontrol.org and http://enhancedbiocontrol.com, with both linked to the

292 underlying URL (http://enhancedbc.tfrec.wsu.edu) hosted at WSU. Adopting the

293 descriptive address names had the added advantage of being easier for visitors and

294 project members to remember.

295 Another consideration while developing the website was to make it fully compatible with

296 mobile and touch enabled devices such as smartphones and tablets. The project's website

297 was designed to recognize the type and size of the visitor's viewing device and render

298 output accordingly. On smartphones, for example, the navigation menu converts into a

299 single interactive drop-down item that remains closed until touched by the viewer thus

300 giving more screen space to the actual page content.

\section{4. Decision Support Tools}


302 The Washington State University Decision Aid System (WSU-DAS) was another

303 important repository for the project's research results. The WSU-DAS serves virtually the

304 entire Washington State tree fruit industry (close to 240,000 acres; NASS, 2014) with

305 pest model predictions and management recommendations (Jones et al., 2010). Users

306 responded in surveys that the WSU-DAS helped with spray timing, lead to better general

307 understanding of IPM and had an estimated value to the industry of approximately $\$ 18.7$

308 M per year in 2014 (Jones and Chambers, 2014).

309 Within the WSU-DAS, the pesticide effects data from OPENED is blended with

310 information from the WSU Crop Protection Guide for Tree Fruit. As in OPENED,

311 pesticide effects on natural enemies in the WSU-DAS are summarized within color

312 gradient bars by pesticide. The intent of this information is that users are able to directly

313 compare the risk of various pesticides to natural enemies, thus helping them make

314 pesticide choices to conserve natural enemies in their orchard.

315 Newly generated natural enemy phenology models for green lacewings and other natural 316 enemies (Jones et al., 2016, this issue) will be incorporated into the WSU-DAS after 317 validation is completed. Users will then be able to see when certain natural enemies are 318 predicted to be present in their orchards, which will help them moderate spray programs 319 during critical parts of the natural enemy life cycle. In conjunction with other information 320 on the WSU-DAS, users will be able to identify pesticides that present the least risk to 321 biological control agents of important secondary pests. An emerging feature of the WSU322 DAS will allow users to create logs of sampled pest or natural enemy numbers as well as 323 applied pesticide applications. In the near future, visualization and synthesis of the user324 entered data can help the user get a better feel for the presence of biological control 325 agents and potential interactions with pesticides and observed secondary pest outbreaks. 326 Ultimately, these integrated features will serve as a self-assessment tool for past, present 327 and future management programs.

328 The functionality of the WSU-DAS is limited to Washington state users due to the state329 specific pesticide recommendations and also because there may be regional differences in 330 emergence patterns of both pests and natural enemies. However, there are other decision 331 support resources available to Oregon and California clientele. These include Oregon 
332 State University's Integrated Plant Protection Center website (http://USPEST.org) and

333 the University of California's Integrate Pest Management (UC IPM) website

334 (http://ipm.ucdavis.edu). The USPEST website integrates degree-day calculators for

335 major pests and diseases and allows users to select their location from a visual map

336 similar to the WSU-DAS. However, there are no management recommendations beyond

337 the general suggestion that sprays need to correspond with pest phenology; nor does it

338 include any models for natural enemies found in tree fruit. The UC IPM website contains

339 a wealth of information about both pests and natural enemies and includes both spray

340 recommendations and a table of pesticide effects on natural enemies. Of the three

341 websites, WSU-DAS has the more complete interface for integrating insect phenology

342 models directly with management recommendations at a location-specific level.

\section{5. Future directions - online courses and mobile apps}

344 Further avenues are being pursued to continue outreach efforts for this project that are

345 intended to provide information and training tools to enhance and stabilize conservation

346 biological control in orchards. Funding leveraged from this project's success is being

347 used to transform the hands-on biocontrol workshops into an interactive online course

348 and to develop a mobile app for identification of common orchard pests and their natural

349 enemies. While stakeholders did not rate online courses as their preferred method of

350 receiving biocontrol information, it is quite possible their response was because they have

351 had no, or very little, experience with dynamic online courses. We believe that a well-

352 developed online course represents a timely and efficient outreach strategy. Making

353 information accessible, intuitive, user-friendly, and engaging is essential for the online

354 course and mobile app to be useful and a success. However, the greatest value of these

355 tools will be stakeholder access to information and training whenever needed and at a

356 time of their choosing, in other words, on-demand.

357 The interactive online course currently under development will be an amalgam of

358 narrated and interactive slides with images, videos and animations. It will also include

359 self-assessment quizzes and self-exploration activities that let the user delve into the

360 many aspects of conservation biological control. As an additional incentive for

361 participating in the online course, users will be able to receive Washington State 
362 Department of Agriculture pesticide applicator re-certification credits upon completing

363 the course. In a broader perspective, the online course could be incorporated into a future

364 IPM certification course or degree program in orchard management. This multi-purpose

365 use of online resources could further optimize the use of valuable Extension resources

366 (time and money) by reducing redundancy in the educational process.

367 An orchard pest and natural enemy identification app is a logical transition from printed

368 field guides to smartphones and tablet computers that most stakeholders already use and

369 carry with them in the orchard. This app would include pictures of common orchard pests

370 and natural enemies showing different life stages currently found in the printed guides.

371 Unlike the printed versions, users will be able to search using an identification key or

372 browsing through the images by type of insect or its characteristics or even by prey or

373 host. The app would also include information about the biology of the natural enemies,

374 their host or prey, their phenology and how certain pesticides affect them. Although there

375 are a few mobile apps for insect identification, including the University of Florida iPest

376 1-3 for urban pests, FMC's Ag PhD Guide for field crop pests and a few general field

377 guides for North American insect and spider identifications

378 (https://itunes.apple.com/us/app/ipest2/id398420454?mt=8;

379 http://www.agphd.com/resources/ag-phd-mobile-apps/ag-phd-field-guide/), this will be

380 the first mobile field guide specific to pests and natural enemies in orchard ecosystems

381 for the Pacific Northwest.

\section{6. Conclusions}

383 In the face of ever-decreasing resources available for Extension services there is a clear

384 need for supplementing educational programs with easily accessible and low-

385 maintenance resources. Digital resources in the form of web pages, videos, downloadable

386 materials, online courses, and mobile apps are needed to fill the gaps when extension

387 personnel are unavailable to supply information directly. It is important to note that the

388 existence of digital resources does not replace the need for Extension educators, but

389 rather compliments their outreach activities and multiplies their influence. There are also

390 stakeholders that are either unable or resistant to adapting to new technologies such as the

391 Internet, smartphones and tablet use. For these reasons, workshops and other live 
392 interactions are still necessary to insure that the information is understood and used

393 appropriately, as well as to reach the technological holdouts. With the completion of our

394 extension program, this project leaves a legacy of digital resources that will continue to

395 provide information transfer in the years to come.

\section{Footnotes}

$398{ }^{1}$ Data from several pesticide effects databases and studies were compiled and added to

399 OPENED. These sources include: USDA-NIFRA SCRI Project "Enhancing Biological

400 Control in Western Orchards”, USDA-IFAFS \& USDA-RAMP Projects “Areawide

401 Codling Moth Control Program II, Washington State University Crop Protection Guide,

402 Koppert Biological Systems, International Organization for Biological Control (IOBC),

403 University of California Extension, Cornell University, Ohio State University and

404 Pennsylvania State University.

\section{Acknowledgements}

407 We extend our appreciation to the research personnel and technical support of the

408 laboratories from Washington State University, Oregon State University, University of

409 California Berkeley and USDA-ARS Yakima Agricultural Research Laboratory. Funding

410 and support of this project was provided through USDA-SCRI Grant No. 2008-04854

411 and matching funds from Washington Tree Fruit Research Commission, Washington

412 State Commission on Pesticide Registration, California Walnut Board, and Hood River

413 (Oregon) Pear Growers. Funding for the preparation of this publication was provided in

414 part through funding from the Washington State Department of Agriculture-Specialty

415 Crop Block Program Grant No. K1268. 


\section{References}

418 Alston, J.M., Norton, G.W., Pardey, P.G. 1995. Science under scarcity: Principles and 419 practices for agricultural research evaluations and priority setting. Cornell University 420 Press, New York.

421 Beers, E.H., Brunner, J.F., Walsh, D., Grove, G., Smith, T., Layne, D., Davenport, J., 422 Daniels, C., Kangiser, J, Klaus, M. 2015. Crop protection guide for tree fruits in 423 Washington. EBO419 online. http://www.tfrec.wsu.edu/pages/cpg/ (last accessed:

424 November 10, 2015).

425 Beers, E.H., Mills, N.J., Shearer, P.W., Horton, D.R., Milickzy, E., Amarasekare, K.G., 426 Gontijo, L.M. 2016a. Nontarget effects of orchard pesticides on natural enemies: Lessons 427 from the field and laboratory. Biol. Control. this issue

428 Beers, E.H., Horton, D.R., Miliczky, E. 2016b. Pesticides used against Cydia pomonella 429 disrupt biological control of secondary pests of apple. Biol. Control. this issue

430 Bonlender, B. 2013. Annual report on broadband in Washington.

431 http://www.commerce.wa.gov/Documents/2013-Broadband-Report-Final.pdf (last 432 accessed: August 27, 2014).

433 Brenner, J., Smith, A. 2013. 72\% of online adults are social networking site users. Pew

434 Research Center. (Aug 5, 2013) http://www.pewinternet.org/Reports/2013/social-

435 networking-sites.aspx (last accessed: August 27, 2014).

436 Cornelisse, S., Hyde, J., Raines, C., Kelley, K., Ollendyke, D., Remcheck, J. 2011.

437 Entrepreneurial extension conducted via social media. J. Online Ext. 49(6) (December

4382011 6TOT1) http://www.joe.org/joe/2011december/tt1.php (last accessed: August 27, 439 2014).

440 Diekmann, F., Loibl, C., Batte, M.T., Yen, M-F. 2012. Judging farmers' willingness to 441 trade distance and taxes for extension services. AEPP 34(3): 454-471.

442 Diem, K.G., Hino, J., Martin, D., Melsenbach, T. 2011. Is extension ready to adopt 443 technology for delivering programs and reaching new audiences? J. Onlin Ext. 49(6) 444 (December 2011 6FEA1) http://www.joe.org/joe/2011december/pdf/JOE_v49_6a1.pdf 445 (last accessed September 17, 2014).

446 eBiz. 2014. Top 15 most popular video websites. 447 http://www.ebizmba.com/articles/video-websites (last update: August 27, 2014).

448 Gadino, A.N., 2012. Summary: audience "clicker" surveys - perspectives of North 449 Central Washington apple growers and consultants.

450 http://enhancedbiocontrol.org/audience survey.html (last accessed: August 27, 2014).

451 Gadino, A.N., Brunner, J.F., Chambers, U., Jones, W.E., Castagnoli, S., Jones, V.P. 2016. 452 A perspective on the extension of research-based information to orchard management 453 decision-makers: Lessons learned and potential future directions. Biol. Control. this issue 
454 Goldberger, J., Lehrer, N., Brunner, J.F. 2013. Adoption of organophospate alternatives

455 in Washington apple IPM programs: Survey evidence from pest management consultants

456 and growers. J. Integ. Pest Mngmt. 4(3):1-8. http://dx.doi.org/10.1603/IPM12023 (last

457 accessed November 18, 2015).

458 Goldberger, J., Lehrer, N., Brunner, J.F., Mills, N., Castagnoli, S. 2016. Biological

459 control adoption in western orchard systems: Results from grower surveys. Biol. Control.

460 this issue.

461 Horrigan, J.B. 2010. Broadband adoption and use in America. OBI Working Paper Series 462 no. 1. Federal Communications Commission.

463 http://online.wsj.com/public/resources/documents/FCCSurvey.pdf (last accessed: May 8, 464 2014).

465 Jones V.P., Brunner, J.F., Grove, G.G., Petit, B., Tangren, G.V., Jones, W.E. 2010. A 466 web-based decision support system to enhance IPM programs in Washington tree fruits. 467 Pest Manag. Sci. 66: 587-595. DOI: 10.1002/ps.1913

468 http://onlinelibrary.wiley.com/doi/10.1002/ps.1913/full (last accessed: November 19, 469 2016)

470 Jones, V.P., Chambers, U. 2014. WSU-DAS user survey.

471 http://entomology.tfrec.wsu.edu/VPJ_Lab/DAS.html (last accessed: September 6, 2014).

472 Jones, V.P., Mills, N.J., Brunner, J.F., Horton, D.R., Beers, E.H., Unruh, T.R., Shearer,

473 P.W., Goldberger, J.R., Castagnoli, S., Lehrer, N., Milickzy, E., Steffan, S.A.,

474 Amarasekare, K.G., Chambers, U., Gadino, A., Gallardo, K., Jones, W.E. 2016a. From

475 planning to execution to the future: A overview of a concerted effort to enhance

476 biological control in apple, pear, and walnut orchards in the western U.S. Biol. Control.

477 this issue.

478 Jones, V.P., Mills, N.J., Shearer, P.W., Unruh, T., Horton, D., Miliczky, E.R., Melton, T., 479 Baker, C.C., 2016b. Using plant volatile traps to develop phenology models for natural 480 enemies: An example using Chrysopa nigricornis (Burmeister) (Neuroptera:

481 Chrysopidae). Biol. Control. this issue.

482 Jones, V.P., Unruh, T.R., Horton, D.R., Mills, N.J., Brunner, J.F., Beers, E.H., Shearer, 483 P.W. 2009. Tree fruit IPM programs in the Western United States: The challenge of 484 enhancing biological control through intensive management. Pest Manag. Sci. 65: 1305485 1310. DOI: 10.1002/ps.1839 http://onlinelibrary.wiley.com/doi/10.1002/ps.1839/full (last 486 accessed: November 19, 2016)

487 Kallioranta S.M., Vlosky, R.P., Leavengood, S. 2006. Web-based communities as a tool 488 for extension and outreach. J. Online Ext. 44(2) (April 2006 2FEA4)

489 http://www.joe.org/joe/2006april/a4p.shtml (last accessed: August 27, 2014).

490 Kinsey, J. 2010. Five social media tools for the extension tool box. J. Online Ext. 48(5) 491 (October 2010 5T0T7) http://www.joe.org/joe/2010october/tt7.php (last accessed: August 492 27, 2014). 
494 Comparative analysis of pesticide effects on natural enemies in western orchards: a

495 synthesis of laboratory bioassay data. Biol. Control. (this issue).

496 NASS. 2009. Farm computer usage and ownership (August 2009). USDA National

497 Agricultural Statistics Service. Washington, DC. SpSy9 (09).

498 http://usda01.library.cornell.edu/usda/nass/FarmComp//2000s/2009/FarmComp-08-14-

499 2009.pdf (last accessed: September 3, 2014).

500 NASS. 2013. Farm computer usage and ownership (August 2013). USDA National

501 Agricultural Statistics Service. Washington, DC. ISSN: 194900887.

502 http://www.nass.usda.gov/Publications/Methodology_and_Data_Quality/Computer_Usag

503 e/08_2013/fmpc0813.pdf (last accessed: September 3, 2014).

504 NASS. 2014. Noncitrus fruits and nuts 2013 summary. Washington, DC.

505 http://usda.mannlib.cornell.edu/usda/current/NoncFruiNu/NoncFruiNu-07-17-2014.pdf

506 (last accessed: August 28, 2014).

507 Ratchford, C.B., 1984. Extension: unchanging, but changing. J. Online Ext. 22(5).

508 (September 1984 5FEA1). http://www.joe.org/joe/1984september/a1.php (last accessed

509 September 17, 2014).

510 Ray, C.D. 2007. The virtual extension specialist. J. Online Ext. 45(2). (April 2007

511 2FEA6). http://www.joe.org/joe/2007april/a6.php (last accessed: August 27, 2014).

512 Schneider, S.B., Brock, D-J.P., Lane, C.D., Meszaros, P.S., Lockee, B.B. 2011. Using

513 information technology to forge connections in an extension service project. J. Online Ext.

514 49(6). (December 2011 6FEA5). http://www.joe.org/joe/2011december/a5.php (last

515 accessed: September 3, 2014).

516 Trede, L.D., Whitaker, S. 1998. Beginning farmer education in Iowa: Implications to

517 extension. J. Online Ext. 36(5) (October 1998 5FEA3).

518 http://www.joe.org/joe/1998october/a3.php (last accessed: September 3, 2014).

519 Urbanowitz, S.C., Wilcox, M.D. 2013. Examining Extension's capacity in community 520 resources and economic development: viewpoints of extension administrators on the role 521 of community resources ad economic development in the Extension portfolio. J. Online

522 Ext. 51(5). (October 2013 5FEA2). http://www.joe.org/joe/2013october/a2.php (last 523 accessed September 17, 2014).

524 Vine, C.A., Watts, L.H., Parks, W.R. 1963. Extension's future. J. Ext. winter 1963. 525 http://www.joe.org/joe/1963winter/1963-4-a7.pdf (last accessed Sepember 16, 2014).

526 Warner, M.E., Hinrichs, C., Schneyer, J., Joyce, L. 1998. From knowledge extended to 527 knowledge created: challenges for a new extension paradign. J. Online Ext. 36(4).

528 (August 1998 4RIB1). http://www.joe.org/joe/1998august/rb1.php (last accessed

529 September 17, 2014). 
530 Zickuhr, K., Smith, A. 2012. Digital differences. Pew Research Center. (Apr. 13, 2012).

531 http://www.pewinternet.org/Reports/2012/Digital-differences.aspx (last accessed: August 532 27, 2014).

533

534 
535 Figure 1. Project website navigation structure. Major categories are shown as white text 536 on black; subcategories are shown as black text on green; subpages are shown as black 537 text on grey under their respective subcategories. The actual appearance and behavior of 538 the navigation menu is dependent on the type of browser used by the site visitor.

540 Figure 2. Screen shot of the interactive visual table on pesticide effects on natural 541 enemies. Moving a mouse cursor over or touching on the natural enemy images or the 542 words "Acute" and "Sublethal" activates an information pop-up box. Shown here is an 543 example of the information box for the acute effects of Delegate on Chrysoperla carnea 544 (http://enhancedbiocontrol.org/PE.html).

546 Figure 3. Screen shot of the Orchard Pesticide Effects on Natural Enemies Database

547 (OPENED) with apple, codling moth and leafroller selected as crop, target pest and 548 secondary pest, respectively.

550 Figure 4 . The trend in website usage based on total and monthly page views. The 551 numbered monthly peaks correspond to known activities discussed in the article (1-

552 website updates, 2 - visits prior to short course, 3 - launch of OPENED).

554 Table 1. Comparison of percent computer usage and Internet access by farms during 2009

555 (beginning of project) and 2013 (final project year) between targeted states and national 556 averages.

557 Table 2. Comparison between of the total number of growers and percentage of survey 558 respondents reporting use of university websites as a source of management information. 


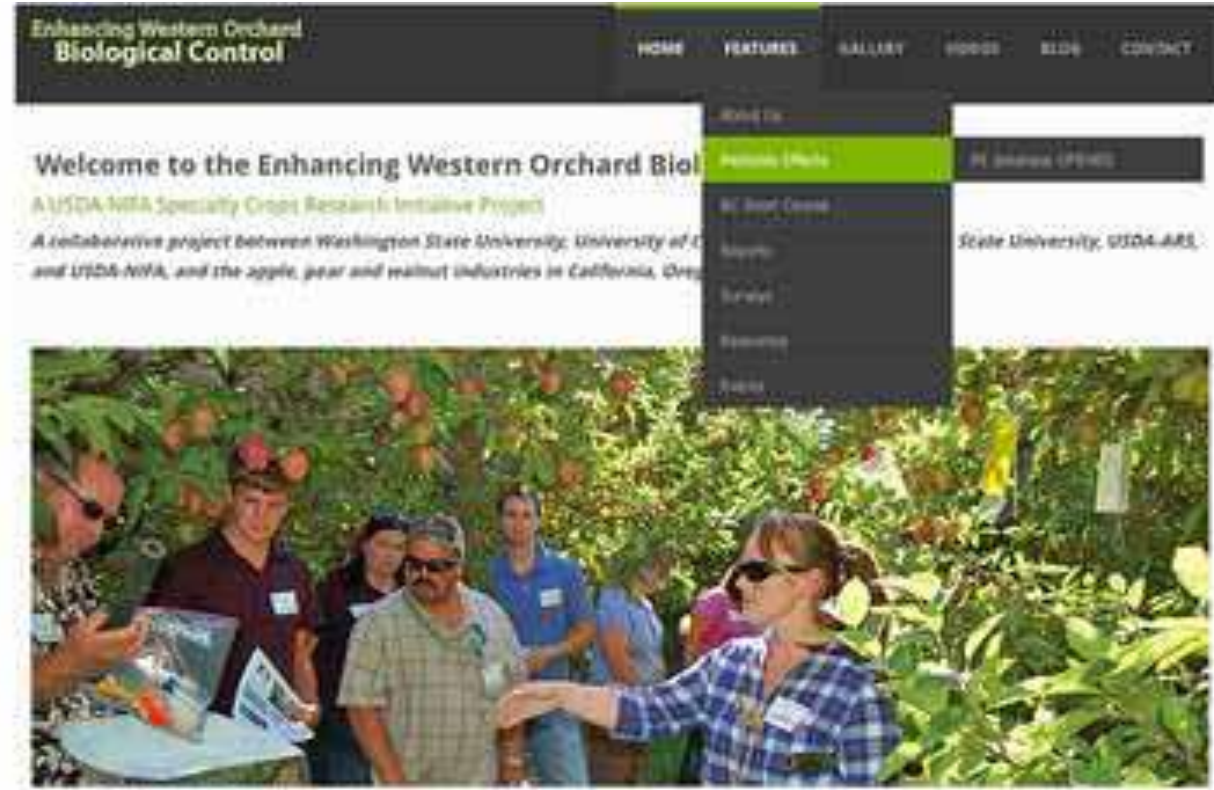

Simnse Orourn Ne is workohap

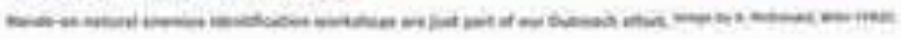

$0 \times 0$

(3) Wov Wor Air

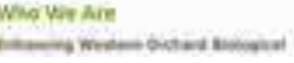

(-) Ment Our Kestainh

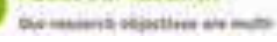

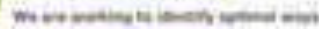

- Oor Divireath Wintan

\begin{tabular}{|c|c|c|c|c|c|c|c|}
\hline & & & & & $\cos =$ & - & \\
\hline & -43 & $\frac{t}{-55}$ & -73 & -62 & -88 & -54 & -28 \\
\hline & -12 & -36 & -96 & -74 & -99 & -91 & -77 \\
\hline & $=$ & $=$ & $=$ & $\Xi$ & $=$ & \pm & - \\
\hline & -100 & -100 & -96 & -94 & -100 & -39 & -39 \\
\hline & $=$ & $\approx$ & 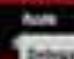 & 2 & $=$ & $\approx$ & $\approx$ \\
\hline & +5 & +10 & & $\ldots$ & -100 & -66 & -32 \\
\hline & $=$ & $=$ & & $x_{N}$ &  & $=$ & $=$ \\
\hline & -87 & .84 & 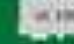 & & -100 & -44 & $=-11$ \\
\hline & $=$ & $=$ & $=$ & $=$ & 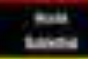 & $\underline{m}$ & 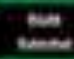 \\
\hline & -3 & -32 & -43 & -16 & -39 & +3 & +12 \\
\hline & $=$ & $=$ & $=$ & $=$ & $=$ & $=$ & $=$ \\
\hline 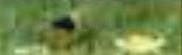 & -59 & -88 & -83 & -7 & -91 & -89 & -23 \\
\hline & $E$ & 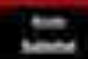 & $=$ & $=$ & $=$ & $=$ & 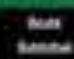 \\
\hline
\end{tabular}


Table 1. Comparison of percent computer usage and Internet access by farms during 2009 (beginning of project) and 2013 (final project year) between targeted states and national averages.

\begin{tabular}{lcccccccc}
\hline & \multicolumn{2}{c}{$\begin{array}{c}\text { \% Farms with } \\
\text { computer access }\end{array}$} & $\begin{array}{c}\text { \% Farms owning } \\
\text { or leasing } \\
\text { computers }\end{array}$ & $\begin{array}{l}\text { \% Farms using } \\
\text { computers for } \\
\text { farm business }\end{array}$ & $\begin{array}{c}\text { \% Farms with } \\
\text { internet access }\end{array}$ \\
\hline State & $2009^{\mathrm{a}}$ & $2013^{\mathrm{b}}$ & $2009^{\mathrm{a}}$ & $2013^{\mathrm{b}}$ & $2009^{\mathrm{a}}$ & 2013 & $2009^{\mathrm{a}}$ & $2013^{\mathrm{b}}$ \\
\hline California & 69 & 75 & 68 & 72 & 44 & 44 & 66 & 72 \\
Oregon & 79 & 84 & 75 & 81 & 44 & 48 & 69 & 80 \\
Washington & 81 & 84 & 74 & 81 & 50 & 44 & 77 & 80 \\
United States & 64 & 70 & 61 & 68 & 36 & 40 & 59 & 67 \\
\hline
\end{tabular}

${ }^{\mathrm{a}} 2009$ data were used to predict usage at the start of the project.

b 2013 data were used to evaluate final website reach. 
Table 2. Comparison between of the total number of growers and percentage of survey respondents reporting use of university websites as a source of management information.

\begin{tabular}{lccc}
\hline Audience group & $\begin{array}{c}\text { Total \# } \\
\text { Growers }\end{array}$ & $\begin{array}{c}\text { \% Survey } \\
\text { Returns }\end{array}$ & $\begin{array}{c}\text { \# Using Web } \\
\text { Resources }\end{array}$ \\
\hline California walnut growers $^{\mathrm{a}}$ & 2688 & 21 & 210 \\
Pacific Northwest pear growers $^{\mathrm{b}}$ & 1001 & 36 & 214 \\
Washington apple growers $^{\mathrm{c}}$ & 2155 & 25 & 199 \\
\hline Totals & 5844 & & 623
\end{tabular}

${ }^{a}$ CA walnut grower numbers extracted from Goldberger and Lehrer, 2016, this issue.

${ }^{\mathrm{b}}$ Combined WA and OR pear grower numbers extracted from Goldberger and Lehrer, 2016, this issue.

${ }^{\mathrm{c}}$ WA apple grower numbers extracted from Goldberger et al., 2013. 


\section{HOME FEATURES $\nabla$ GALLERY $\nabla$ VIDEOS BLOG CONTACT}

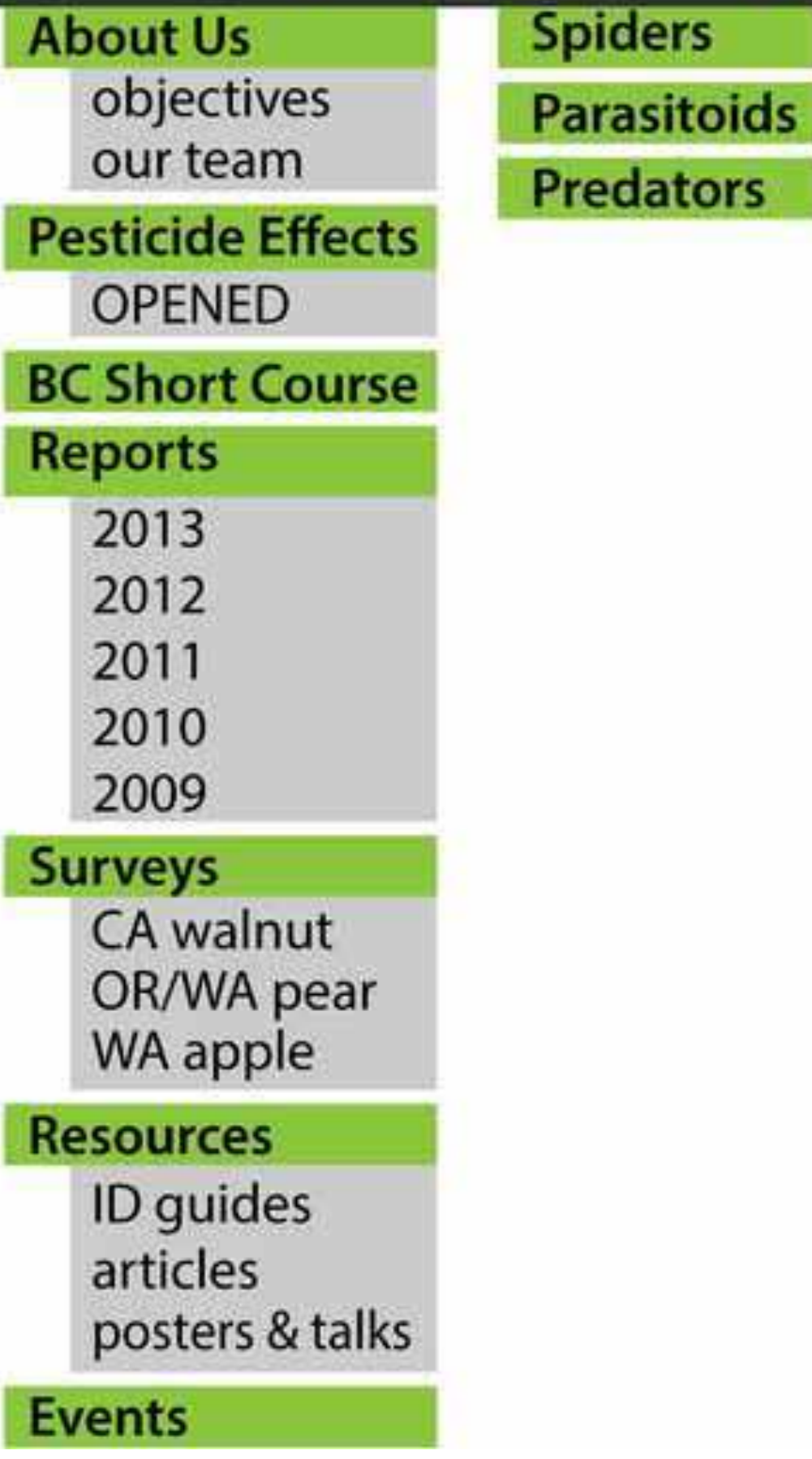

Resources

ID guides

articles

posters \& talks

\section{Events}




\begin{tabular}{|c|c|c|c|c|c|c|c|}
\hline & Altacor & Exirel & Delegato & fimon & Warilor & Kumulus &  \\
\hline & -43 & -55 & -73 & -62 & -88 & -54 & -28 \\
\hline & -12 & -36 & -96 & -74 & -99 & -91 & -77 \\
\hline & 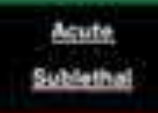 & sule & sites & 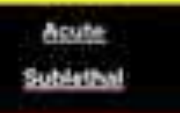 & 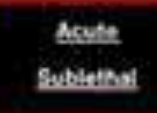 & Acole & sole \\
\hline & -100 & -100 & -96 & -94 & -100 & -39 & -39 \\
\hline & save & soves & \multirow{4}{*}{\multicolumn{2}{|c|}{ 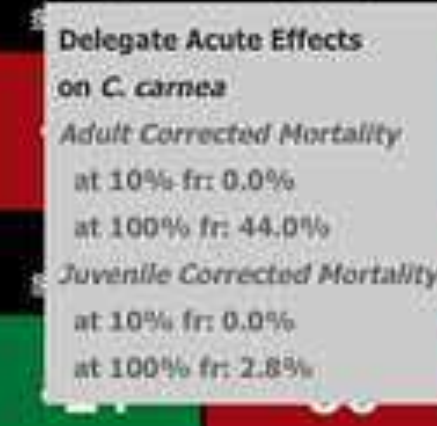 }} & sines & somen & thoth \\
\hline & +5 & +10 & & & -100 & -66 & -32 \\
\hline & sovere & sute & & & Asule & 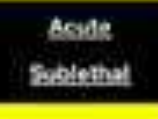 & sis \\
\hline & -87 & -84 & & & -100 & -44 & -11 \\
\hline & swate & save & sule & soveres & 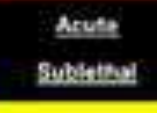 & solve & sosent \\
\hline & -3 & -32 & -43 & -16 & -39 & +3 & +12 \\
\hline & scose & Anter & sover & Sister & sonte & Asule & solet \\
\hline$\Rightarrow$ & -59 & -88 & -83 & -7 & -91 & -89 & -23 \\
\hline & 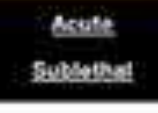 & stonte & sater & 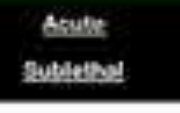 & 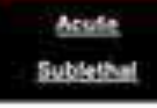 & sonter & sosent \\
\hline
\end{tabular}


Ellect rasings based on poovitation groveth imascas Ranking of negabve pesticide inosda:

none or low moderate

high

mortality, eflects on the

hatched ete.

As cher noings ave basec

on acute tor cily Le. poitally wipin es nours of $n=7$ studies pestiode exposure.

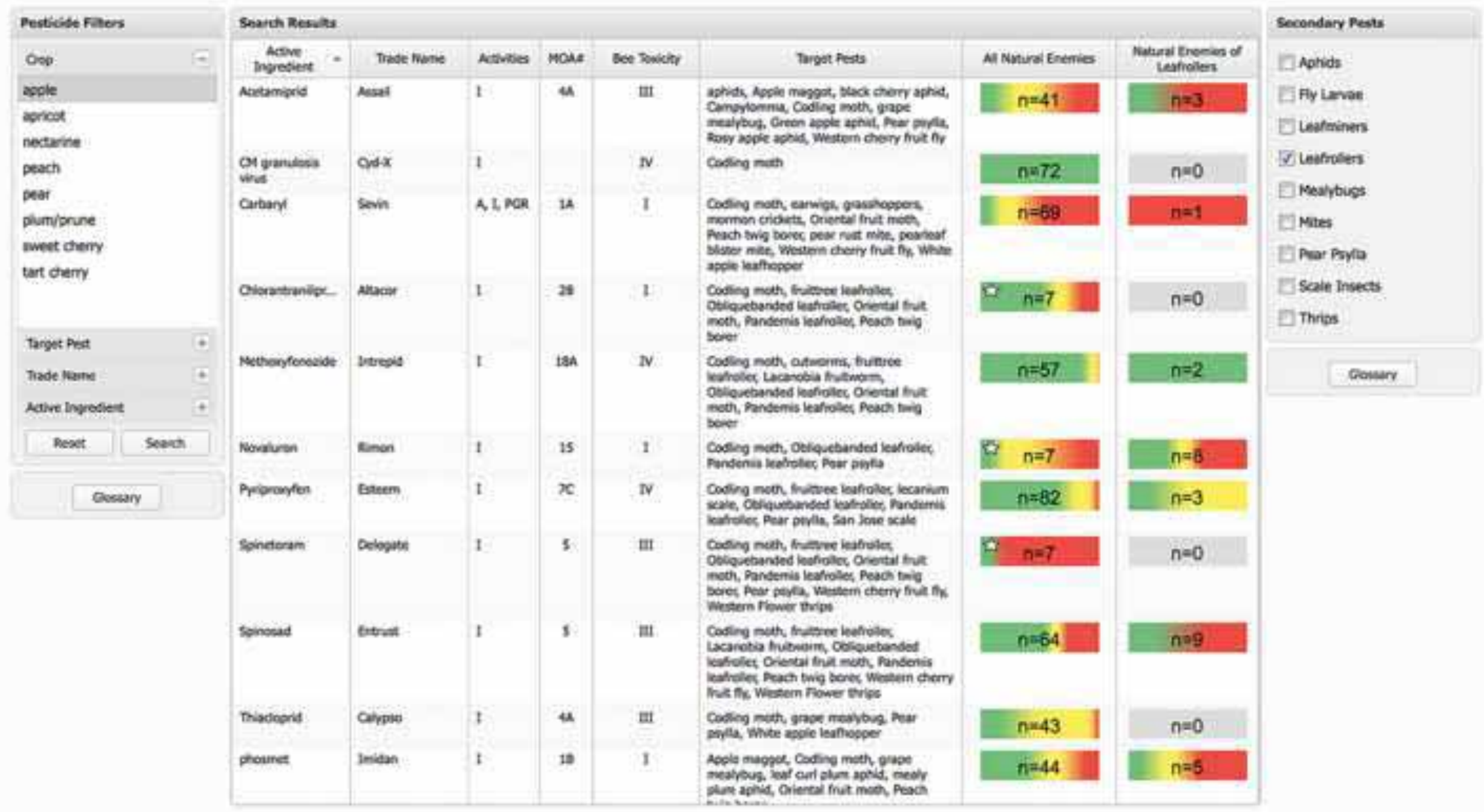




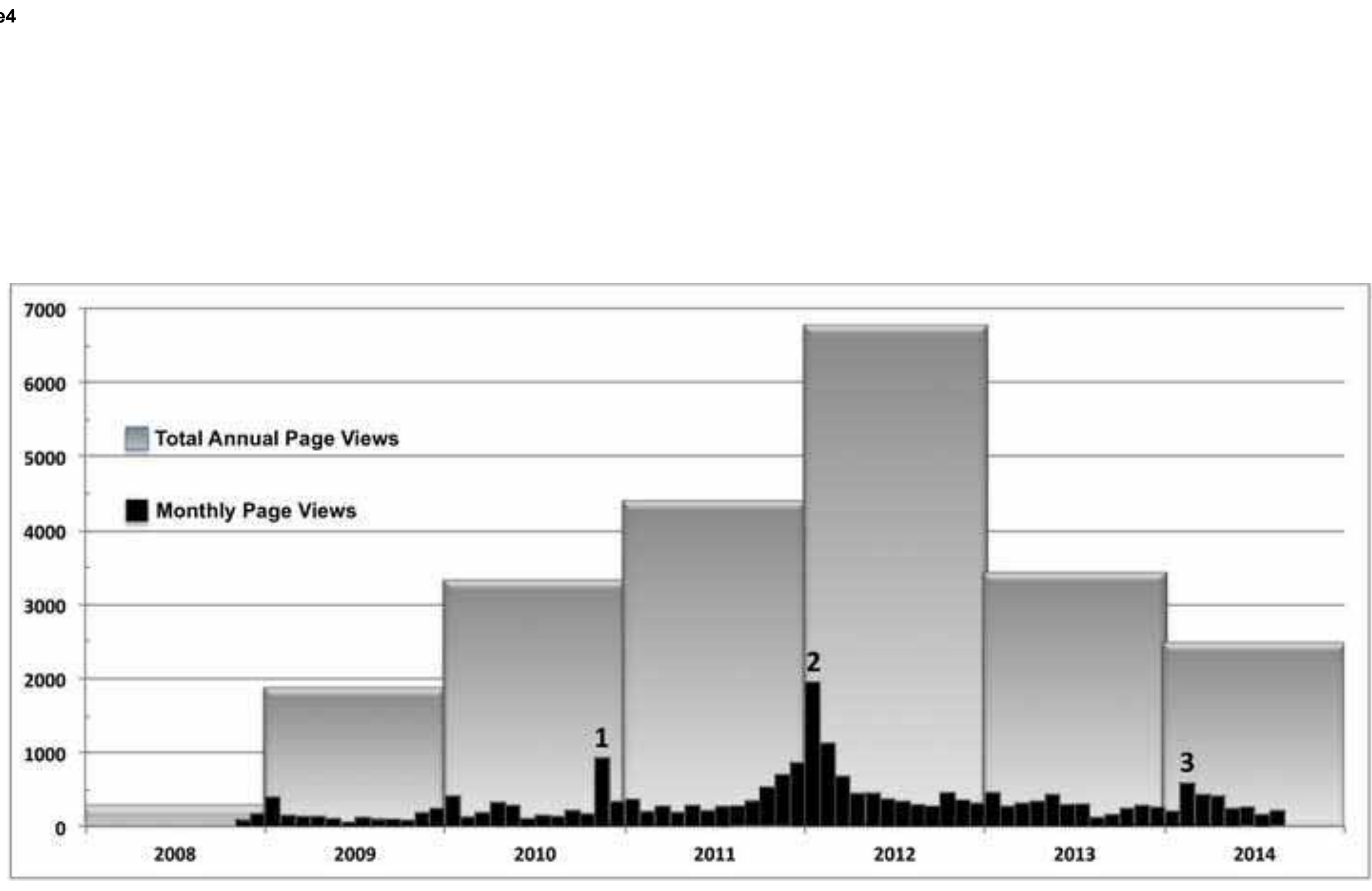

